\title{
BIBLIOTHERAPEUTIC TECHNIQUES FOR USE BY SOCIAL WORKERS AND CAREGIVERS
}

\section{Iralda Oelofsen, Herman Grobler}

\section{INTRODUCTION AND PROBLEM STATEMENT}

All children need to grow up with a sense of belonging and security in order to maintain healthy relationships later in life (Erikson, 1969:239; McWhirten, 2007:189; Toerien, 2001:31). Belonging is a basic human need that has to be met before certain other needs, such as self-actualisation and self-esteem, can be fulfilled (Erikson, 1969:238; Maslow, 1970:43; Max-Neef, 1991:33). A lack of a sense of belonging leads to feelings of rejection, loneliness and an inability to engage in future relationships (Ding \& Littleton, 2005:i). Children who do not experience this sense of belonging can easily become involved in gangster activities, promiscuity or substance dependence in order to secure a false sense of belonging (Brendtro, Brokenleg \& Van Bockern, 2002:9). Ideally, this need for belonging should be fulfilled within the primary family situation. However, the reality is that many children in South Africa do not live in what is generally regarded as the primary family, namely a family with two parents (Holborn \& Eddy, 2011:1), but come from fractured families. Children from fractured families in disadvantaged communities have more complex needs to be met in order to feel secure (Ding \& Littleton, 2005:iii; Holborn \& Eddy, 2011:7; Minuchin, Colapinto \& Minuchin, 2007:10; Toerien, 2001:31; Yuen, 2005:7).

Children living in disadvantaged communities face more hardships than their peers in more affluent communities, because disadvantaged communities are characterised by a lack of resources as well as poverty, violence and gangster activities (Elliot, Menard, Rankin, Elliot, Wilson \& Huizinga, 2006:4; Minuchin et al., 2007:8). Social and psychological services are often unavailable in these communities and caregivers do not always know how to support the children in their care emotionally. The caregivers do not always realise this need for emotional support and have to be made aware of it and equipped with ways to provide it.

Children from fractured families in disadvantaged communities also do not always have a sense of belonging with their primary caregivers, and are therefore prone to fall prey to destructive and false structures of belonging, such as gangs (Beck \& Malley, 2003; Hamilton, 2005). Alternative ways of helping children who lack a sense of belonging should therefore be investigated. According to Pardeck (2005:47), the use of bibliotherapeutic techniques may be one such alternative approach and can be useful in helping children deal with emotional and adjustment problems. Malchiodi and GinnsGruenberg (2008:171) mention that successful bibliotherapy moves children from their personal crises towards recovery through placing feelings and memories within a larger framework beyond the self.

During the broader empirical research by Oelofsen (2012) on a sense of belonging of children in fractured families from disadvantaged communities, it was determined that 
the need for an intervention programme regarding bibliotherapeutic techniques is twofold. Firstly, the social workers expressed a need for such a strategy in order to help the children to secure their sense of belonging within their families (Oelofsen, 2012:187). Secondly, the caregivers had to become aware of the children's needs regarding a sense of belonging. It transpired during the research that the caregivers often lacked the knowledge, resources and motivation to fulfil the children's needs other than the basic needs of providing food and shelter (Oelofsen, 2012:187). Having kept these aspects in mind, the proposed intervention has to consist of various bibliotherapeutic techniques and activities in order to achieve its purpose.

The goal of the research reported in this article was to develop, implement and evaluate bibliotherapeutic techniques for the use of social workers in disadvantaged communities in order to create a sense of belonging in children in their middle childhood, as well as to train the caregivers in becoming aware of the importance of a sense of belonging and the role they could play in utilising bibliotherapeutic techniques.

\section{DEFINITIONS OF CONCEPTS}

\section{Fractured family}

Minuchin et al. (2007:6) define family as a special kind of system with structure, patterns and properties that provide stability and organise change. A fractured family is one that does not consist of two married biological or adoptive parents (Holbern \& Eddy, 2011). In practice, this means that children from fractured families live with only one parent, with grandparents, foster parents or other family members. To avoid confusion, the general term "caregiver" is used in the study to refer to the people responsible for the children.

\section{Caregiver}

For the purpose of this study the general term "caregiver" is used and refers to the people responsible for the children. The children who took part in the study were in the care of various people, such as a single parent, grandparent, other family member or foster mother. According to Barker (2003:57), a caregiver is one who provides for the physical, emotional and social needs of another person who is often is a dependant and cannot provide for his or her own needs.

\section{Children in their middle childhood}

Middle childhood refers to the years between the ages of six and 12, when most children are in primary school and before the onset of the adolescent years (Meyer, Moore \& Santrock, 2006:227; Viljoen, 2008:202).

\section{Disadvantaged communities}

Smith, Cowie and Blades (2003:553-663) define the term "disadvantaged" as a relatively enduring condition that results in lower academic achievement at school and reduced opportunities in the wider society. It refers to social and/or cultural characteristics. The area where this study was conducted is a disadvantaged community, 
as there is a lack of infrastructure and resources, and the poverty and unemployment rates are high.

\section{Bibliotherapeutic techniques}

Bibliotherapy entails the use of books and stories in order to help people to overcome emotional problems (Fitzgerald, 2007; Recob, 2008). For the purpose of this study bibliotherapy has been adapted to involve a series of activities (bibliotherapeutic techniques) in order to enhance a sense of belonging in children from fractured families.

\section{RESEARCH METHODOLOGY}

A qualitative research approach was followed, utilising the Design and Develop Model (D \& D model) of intervention research, as described by Rothman and Thomas (1994:4). The specific intervention research model of Rothman and Thomas consists of six phases. For the purpose of this article Phases Three, Four and Five apply, with the focus on the design of the research, the early development and pilot testing of a preliminary intervention programme, as well as its evaluation and the development of an advanced intervention.

The study took place in the northern suburbs of Port Elizabeth and was limited to children between the ages of 6 and 12 years, as well as their caregivers and social workers who work in the area. All the children were from fractured families. The information gained during the empirical research was used to compile bibliotherapeutic techniques for the use of social workers. It also transpired that the caregivers were unaware of the needs of the children regarding a sense of belonging. Therefore this shortcoming was also addressed in the context of utilising bibliotherapeutic techniques with their children.

\section{PHASE 3: DESIGN PHASE OF INTERVENTION RESEARCH}

In this phase it was necessary to design an observational system and to specify procedural elements of the intervention. The purpose of an observational system is to provide feedback for refining early prototypes (De Vos \& Strydom, 2011:482). The persons who have to implement the final programme, namely the social workers, are therefore the ideal group to be involved in the observational system.

Several problems emerged from the empirical research, which were identified as issues that needed to be addressed.

- The children live in poor, overcrowded conditions.

- They are subjected to violence, gang activities, use of drugs and alcohol abuse on a daily basis.

- The caregivers are overwhelmed by, and expressed a feeling of helplessness regarding, the conditions in the community.

- The children feel insecure and helpless in their situation.

- Not all of the children have a healthy, trusting relationship with their caregivers.

- The children have a need for nurturing interaction with their caregivers. 
- The children express a need to play and have fun activities with their caregivers.

- The caregivers are unaware of these needs of the children and focus mainly on meeting the basic needs such as food and shelter.

- Resources in the community, such as schools, churches and reliable neighbours, can be utilised to enhance a feeling of belonging and safety in the children.

- The social workers express a need for an intervention model that utilises bibliotherapeutic techniques to enhance a sense of belonging in the children.

- The caregivers are not equipped to fulfil the children's needs and the social workers would have to empower them to enhance a sense of belonging amongst the children in their care.

These identified problems were used to create observational tools, which are discussed later in this article, to be used together with the bibliotherapeutic techniques. The purpose was to evaluate whether the techniques are workable and applicable to the target system, namely the children in their middle childhood in fractured families from disadvantaged communities.

In order to develop a strategy for bibliotherapeutic techniques to be utilised by social workers, several other functional elements in other programmes were reviewed, as outlined below.

\section{Gestalt play therapy}

Gestalt play therapy, as developed by Oaklander (2003:143-155), relies on basic Gestalt principles and concepts. Elements of this approach were used because they address key aspects, as transpired from the literature, that are necessary in facilitating a sense of belonging (Alderfer, 1989:351; Erikson, 1969:238; Max-Neef, 1991:33), such as awareness, the children's process, unfinished business, holism, change, organismic selfregulation, empowerment, the phenomenological approach and field theory (Barber, 2006:36; Joyce \& Sills, 2010:27; Kirchner, 2004; Perls, 1973:7; Sharf, 2004:243; Yontef, 2005:300).

\section{Attachment theories}

Attachment forms the foundation for a sense of belonging (Berlin, 2005; Erikson, 1969:238; Karen, 1998:15; Maslow, 1970:43; Santrock, 2006:332) and must therefore be taken into account in the formulation of techniques that would enhance a sense of belonging.

\section{The importance of play}

Play, just like stories, is a natural, part of childhood (Hepworth \& Larsen, 1993:623). It is essential that children should have ample opportunity to play in their preschool and middle childhood years, as this is vital for their development and wellbeing (Talbot \& Thornton, 2009:13). It is regarded a basic right of children to play, as recognised in the United Nations Convention on the Rights of the Child (United Nations, 1989: Art. 31) and in the African Charter on the Rights and Welfare of the Child (African Charter, 
1990: Art. 12). Talbot and Thornton (2009:9) stress that play should not be regarded as an optional extra, but as a basic right of children.

\section{Theraplay}

Theraplay is described as an engaging, playful, relationship-focused treatment method that is interactive, physical, personal and fun (Booth \& Jernberg, 2010:3; Lucas, 2000:2; Morin, 1999:xii). Elements of theraplay can be used with great success in the proposed intervention, as it is easy to understand and does not acquire a high level of education, which makes it ideal for the caregivers in a disadvantaged community. Miller, Lender, Rubin and Lindaman (2010:405) argue that children from fractured families have a greater need for sound parenting, empathy and fun, and that theraplay can act as a healthy antidote to a painful past.

\section{Bibliotherapy}

Children have a natural liking for stories (Costello, 2000:45); therefore bibliotherapy can be used with success with children in order to address emotional problems (Burns, 2005:3; Recob, 2008:vii; Sunderland, 2000:3). Children in their middle childhood years may not be able to verbalise their need for a sense of belonging, but by identifying with a character in a story who experiences a similar need, they can work through it and find alternatives to fulfil this need (Kriel, Rademeyer \& Röhrs, 2010:4; Sorensen, 2008:9).

The following elements of bibliotherapy were taken into account when creating the stories for children (Hendricks \& Hendricks, 1998; Pardeck, 1998:5-10; Rubin, 1978:7):

- The intervener must be familiar with the material;

- The children must be able to identify with the plot, setting, dialogue and characters;

- The material selected must express the same feelings or mood as the child;

- The emotional and chronological age of the child must be considered;

- Good coping strategies must be modelled;

- The length and complexity of the material must be appropriate for the child;

- The story must capture the child's attention and interest.

Traditional bibliotherapy that utilises only books to address problems is not a practical approach in a disadvantaged community. The empirical research study found that some of the caregivers were illiterate, the community was poor and it did not have easy access to books and libraries. The proposed intervention thus utilised bibliotherapy in the broad sense of the word and would therefore make use of various activities that can be linked to bibliotherapy by the use of storytelling (Malchiodi \& Ginns-Gruenberg, 2008:171).

In addition to problems listed by participants that needed to be addressed in the intervention, the social workers also had the following requirements for the proposed bibliotherapeutic techniques:

- The techniques must be simple and easy to apply;

- It must relate to the children in the disadvantaged community concerned; 
- Some caregivers are illiterate, therefore the activities they need to do should utilise pictures or games to convey the desired message.

- Everything needed for the techniques must be either supplied to the caregivers or already available, as the caregivers do not have the means or resources to obtain the aids.

The intervention consists of two parts. The first one was for the social workers, where the following procedural elements were required:

- The ability to engage in a meaningful therapeutic relationship with children in their middle childhood;

- A sound understanding of development theories and child development;

- A clear understanding of the importance of a sense of belonging and the effects of a lack thereof;

- An empathic understanding of the realities and challenges of people living in disadvantaged communities;

- A belief that people have the ability to change;

- The desire to help people in difficult situations to look for alternatives within their settings in order to cope with their problems;

- Experience in group work, should the caregivers be trained in a group setting.

The second part of the intervention was focused on the caregivers and took the form of a training programme, where the caregivers are taught the importance of a sense of belonging and ways to create it in the children in their care. A training programme for caregivers in enhancing a sense of belonging in their children was compiled specifically for the use of a professional facilitator, preferably a social worker. It is recommended that the training should take place in a group setting. The following suggestions regarding such group training should be taken into account.

- The caregivers must realise that they are valuable partners in the therapeutic process between the social worker and the children.

- The care that the care caregivers give the children under difficult circumstances must be acknowledged.

- The facilitator must be sensitive to the various educational levels of the caregivers in the group.

- The message that the caregivers have the ability to perform the required tasks must be emphasised.

- The information must be shared in a simple, practical way that everybody can understand.

- The caregivers must buy into the concept that seemingly simple and "useless" activities such as playing a game serve a deeper and important purpose. 
- The caregivers must realise that they have to do the activities together with the children.

- Everything they will need to complete the activities, for example books, crayons, play dough, Prestick, must be provided.

- It is important to have follow-up sessions.

\section{PHASE 4: EARLY DEVELOPMENT AND PILOT TESTING}

\section{Developing a preliminary intervention}

The aspects mentioned in phase three were taken into account in order to develop a preliminary intervention that could serve to enhance a sense of belonging in children from fractured families in disadvantaged communities.

As part of the pilot testing, two social workers were requested to evaluate the prototype of the intervention. The intervention activities were also performed with three children in order to determine whether they were practical and viable. Subsequently some alterations were made on the basis of the comments of the social workers and children.

\section{PHASE 5: PRELIMINARY BIBLIOTHERAPEUTIC TECHNIQUES FOR USE BY SOCIAL WORKERS}

The following bibliotherapeutic techniques were developed for the use of social workers in assisting children who lack a sense of belonging. The techniques are intended to be used over several sessions, depending on the children's circumstances and emotional capacity.

\section{The use of an emotions card}

The purpose of using the emotions card is to enable children who have difficulty in verbalising their feelings to communicate them via pictures of different emotions. It will also help children to identify and understand their emotions. They can be used with all activities where children struggle to communicate their emotions. The facilitator must ask the children to identify a face on the card that reflects their feelings, and then ask what emotion this picture reflects, if the children experience the same feeling, and then proceed to discuss the reason for this emotion. They can then discuss possible activities that will help the children to deal with this emotion, for example, to box a pillow when they are angry.

\section{Assessing my home and community}

This activity was used to assess children's attitudes towards their home and community, as well as to determine with whom they identify, where their sense of belonging is focused and to identify problematic relationships at home.

The children are handed a set of pictures and asked to choose from it those pictures that represent the people in their homes. They must then put these pictures on an outline of a house. The social worker has to determine who each picture represents, whom they will go to if they have a secret, are scared, who they do not want in the house, who is not there but they would have liked to be in the house. From another set of pictures the 
children have to choose the pictures that represent the people in their immediate community. The same questions as above must be asked about the community, in order to determine if the children experience a sense of belonging in the community and if there is any social capital that can be utilised.

\section{Playing snakes and ladders}

The primary purpose of this activity is to enhance the therapeutic relationship between the children and the social worker. It also raises awareness of the activities that create a sense of belonging and identifies aspects that cause unhappiness. This creates opportunities for the social worker to discuss these activities with the children.

The social worker and children play the game on the provided board with a dice and tokens. When a player lands on a picture, the child must explain what is happening in the picture and what feeling the picture generates for him/her. The emotions card can be used as an aid if necessary. They then proceed to determine whether the children have ever experienced a similar emotion, and discuss the cause and results of the events. Feelings about winning or losing can also be discussed. The children can be asked which feelings they liked best, or dislike, and the reasons for this.

\section{Interpreting the story of Tommy the Little Train Car}

The story can be used with younger children who have been placed in alternative care. The social worker must read the story to the children, discuss the emotions in the story, draw parallels between the story and their lives, and help them to identify with the character in the story. They must then develop an insight into the reality of their lives, that life continues despite loss and that the future, although different, is not necessarily bad. Younger children can colour the picture of the train in order to reinforce the message.

\section{Completing the two hearts}

The purpose of this activity is to help the children to identify aspects that cause happiness or sadness. It also gives the children the opportunity to identify alternatives that will create happy and secure feelings. It raises awareness that, although they might have scars, it is possible to become "whole" again. The children are shown pictures of the two hearts.

The social worker must ask the children to describe what the picture of the broken heart looks like, if their hearts ever felt like this. The children or social worker then writes events down that caused the children's hearts to break next to the picture and the emotions caused by this. On the picture of the second heart, the children must be helped to identify people or situations that can help them to make their hearts "whole" again, which they write on the separate parts of the heart. They must discuss what else they need to complete their hearts, after which they can colour and decorate the heart.

\section{Constructing a tree of belonging}

Through this activity the children will gain a better understanding of their family and where they come from. It will make their past more visual and concrete in order to help the children to build their own identity, as well as create a sense of belonging in their 
new family. With the help of a family member the social worker must try to ob tain photos or stories about the children's family of origin.

In the picture of the family tree, the roots represent the children's ancestors, where they live, what they did and any known stories or songs that they used to tell or sing. These can be written on the picture. On the trunk they have to write down the children's grandparents' names, where they live and anything else known about them. The branches represent the children's parents, uncles, aunts, siblings, and anything known about them. If there are no photos available, the children can draw pictures of them. All the information on the tree must then be discussed, for example, who they remember or miss.

The family tree does not have to be technically correct, as long as it makes sense to the children and tells a story about their past and background. On the picture of the Tree of belonging the names of the foster family/new family are written. It must be explained to the children that although they may not be related, all of them are now part of a new tree and that everybody has his/her own place in this tree and are connected because they share one tree (home). The children must be assisted to identify activities and aspects that will help them to feel part of the new family (such as helping with chores and sharing a bedroom with foster child.)

\section{Interpreting the story of a new home for Mia}

The purpose of this story is to explain foster care by means of a story. By reading the story, the social worker must help the children to understand and accept their situation, work through their feelings and determine what will enhance a sense of belonging in their new home.

\section{Completing the puzzle}

Through completing this activity, the children will gain insight into the missing parts of their lives, the feelings these losses cause and create a new puzzle of belonging. The children are given a puzzle to build, but some of the pieces are missing. Their feelings about this incomplete picture are discussed, and they can write on the back of the puzzle which aspects of their lives the other parts represent, and who the missing part represents. The social worker then hands them the missing part, but it is in a different colour from the rest of the puzzle. They can identify what events or people in their lives represent this new piece that completes the puzzle. If they turn the puzzle around, the picture is complete. The social worker must help the children to draw comparisons between this and their lives.

\section{Connect the pictures}

The purpose of this activity is to identify activities that create a sense of belonging for the children, and those that cause them to feel unsafe. The children must connect the pictures on the one side of the paper to corresponding ones on the other side. They must be reassured that there are not any right or wrong answers, and it is only their opinions that count. The pictures and their responses to them must then be discussed and 
connected to situations in their lives, thereby identifying activities that create a sense of belonging for the children.

\section{Creating memory and belonging boxes}

Through this activity the children can be helped to cope with past losses and to gain comfort by remembering the good aspects of the past, as well as to create a sense of belonging in their new family.

With the memory box, the children are asked to talk about all the nice and good aspects they can remember about their previous family/missing/deceased parent. They must then find articles that remind them of the abovementioned, such as a piece of material, beads or photos. The children can write letters to the person concerned and place them in a box. The children then keep the box with them in a safe place; they can take objects out and look at them whenever they feel sad about missing their family.

The belonging box is initially empty. Every time something nice happens in the new family, the children must put something that reminds them of the event in the box (e.g. outing to beach, put shell in box). The children must be helped to identify aspects that create a sense of security and belonging, e.g. foster mom reads story, picture of piglets reminds them of that.

\section{Completing the story of Terry and the gang}

This story conveys the message that sometimes people try to find a sense of belonging in the wrong places and that our choices have an influence on our future. Older children can read the story themselves, or the social worker can read it to them. The children must choose how they will complete the story. The different endings must be discussed and applied to their lives.

\section{Freeing the paper doll}

This activity tells a visual story about how emotions and events from the past can entangle a person and prevent him or her from moving on. With the help of the social worker, the children are asked about the sad or bad things that they think happened to an imaginary boy or girl, represented by the paper doll. For every aspect they mention, a piece of string is wound around the doll's body. Discuss possible alternatives, which can unwind these strings that are strangling the doll. If a satisfactory solution is found, the piece of string can be unwound. Ask if there are any similarities between the doll's story and their own. Discuss the situations and find alternatives. The doll can be coloured.

\section{Telling my own story}

By means of several pictures, the children are asked to create their own stories. The social worker discusses the stories with them, explores the meaning of the characters and draws parallels to their lives. Alternatives can be found and incorporated into the story.

\section{Defining my own identity}

A picture of a spaceship is used and the children are asked to pretend they are some of the aliens on the spaceship that has landed in the front garden. They must explain to the social worker what they find in the house and street, who and what they like and dislike, 
and whether they would like to stay there. The purpose is to determine how the children perceive themselves and their environment. When the story is discussed, the social worker asks the children if this is similar to their own lives and what they would like to change.

\section{PRELIMINARY TRAINING TO CREATE AWARENESS IN CARE- GIVERS REGARDING THE NEED FOR A SENSE OF BELONGING}

From the caregivers' responses during the empirical research it became clear that they were unaware of the need for a sense of belonging in the children in their care. In order to help them to strengthen the emotional bond with their children, it is necessary that the social workers train the caregivers regarding the importance of a sense of belonging and ways in which to enhance it.

The purpose of the training session for the caregivers was primarily to raise awareness of the need for a sense of belonging in the children in their care, as well as introducing them to activities that will enhance the children's sense of belonging. The caregivers' intellectual levels and social circumstances have to be taken into account in developing the training. The training took place in a group setting, as the interaction between the caregivers served as extra motivation to complete the activities. The session lasted about three hours.

\section{Contents of programme}

The group members were welcomed and the purpose of the meeting was explained, that is, to teach them new, simple activities through which they can improve the wellbeing of the children in their care. The facilitator was sensitive to the educational levels of the caregivers, for example, not assuming that all could read and write. Playing a short icebreaker game, like dividing into two teams and competing to see which team can keep a balloon afloat the longest, helped them to relax and reminded them of the value and fun of playing games. The discussion then proceeded to give them background knowledge regarding the importance of a sense of belonging in children.

\section{Human needs}

With the aid of a simplified diagram of Maslow's hierarchy of needs (Maslow, 1970:340), the caregivers were informed on basic human needs. Practical examples that they could understand were used to illustrate why the primary needs must first be met before the next need can be addressed. To capture their interest pictures of Bowlby's (1982) well-known monkeys in the wire cages were shown and explained.

A sense of belonging was explained in simple language, as a feeling to feel secure, safe, at ease, part of a family, group or community (Brendtro et al., 2002:12). With the aid of Maslow's (1970:340) diagram it was explained that all other needs depend on the successful satisfaction of this need, as a person can only grow emotionally if he feels safe and secure. Erikson's theory was explained that a baby has to develop a sense of safety, security and trust with its mother, otherwise it will grow up with a sense of distrust (Erikson, 1969:238). 


\section{The results of non-belonging}

The results of non-belonging were discussed, like feelings of distrust and insecurity, poor school progress (because nobody cares), drug and alcohol abuse, involvement in gangster activities or sexual relationships at a young age. It is emphasised that if this cycle is not broken, the children will eventually become parents who are unable to provide a sense of belonging to their children.

The caregivers had to become aware that all the children in their care were from fractured families and that they were already exposed to trauma and violence, which could be an indication that they did not develop a trusting relationship with their initial primary caregivers. This made them much more susceptible to the above dangers.

It was important that the caregivers understood the necessity to intervene at this stage of their children's lives, while the children were still in their middle childhood. The caregivers therefore had to make an extra effort to reach out to the children and create in them the feelings that they were accepted for who they are - that they were loved and worthy, warts and all.

\section{Activities to create a sense of belonging}

It was of utmost importance that the caregivers understood that these activities were not meant to keep bored children out of mischief, but that the whole purpose of every activity was that they should spend time with the children and that everything should be done with the children. The purpose of all the exercises was to strengthen the bond between them and to fulfil the children's needs for interacting in a playful way with their children.

\section{Six things a child needs to hear}

Every caregiver was handed a laminated card with the six things a child needs to hear on it (Girls \& Boys Town, 2011). They were asked to stick this card up somewhere in the house where everybody would see it, and try to say at least one of the six things to the children on a daily basis.

\section{Caring deeds}

The caregivers had to be aware of the fact that deeds speak much louder than words, and that the children would much rather experience a sense of belonging by what they did than by what they were told. It was explained that although the activities might seem childish and like a waste of time, this was what the children expressed a need for and were therefore worth trying out. They were thus asked to do as many as possible of the following activities.

Rituals: The importance of family rituals was explained to the caregivers. Examples are to have story telling time at bed time, to sing together on Sunday evenings, and to have a special treat on someone's birthday. This will help to make the children feel that they belong in the family and are important. The caregivers had to think of something they can start as a ritual in their families. 
Own space: The caregivers were encouraged to create a space in the house, however small, for each child that he or she can call his/her own. Even if the children have to share a bed, each child should at least have a bag, box or shelf where they can keep their own stuff that is out of bounds for the other family members. This creates a sense of self-worth and belonging for the children. This is also a way for them to learn important values such as respect for someone else's belongings.

Stories: All children love stories, and even if the family do not possess any books, this should not stop them telling stories to their children. The caregivers were encouraged to tell the children stories of their own childhood, how they overcame difficulties and how they lived.

Playing of games: The caregivers had to name the games they used to play as children and were encouraged to teach these games to their children and, when it was physically possible, play these games with the children. Any other physical games, such as hide and seek, could also be played.

Nurturing activities: It was explained to the caregivers that whenever a basic need is not met, this need remains with the person until it is met at a later stage. During the empirical research the children expressed the need to be nurtured. The caregivers were therefore encouraged to focus on nurturing activities, such as bathing younger children, combing their hair, applying hand lotion, massaging of their backs and tucking them into bed. It was stressed that special care had to be taken with these activities, especially when a child was subjected to abuse. Safe places to touch, like hands, arms, heads and shoulders, as well as great sensitivity to the children's needs and reactions were explained. The same applied to putting a younger child on the lap, and for hugs and cuddles.

Emotions card: Each caregiver was handed a laminated card with faces representing different emotions, as well as an arrow made of paper that could be stuck on a face. They had to put this card up somewhere in the house and ask the children every morning to select a face that represented their feelings. These feelings should then be discussed.

Snakes and ladders: An adapted, laminated board of snakes and ladders, tokens and a dice were provided to each caregiver. The game was explained, especially the use of the pictures, which all represented belonging or a lack thereof. Whenever somebody landed on a picture, they had to discuss the picture and the feelings it provoked.

Play dough: Each caregiver was provided with a tub of play dough. It was stressed that they had to play with the children, that there were no rules, but that everybody could do with the dough whatever they wanted to, as long as they discussed the objects and tried to tell a little story about the object they created.

Colouring books and crayons: They had to use the provided books and crayons with the children. When they completed the picture, they had to discuss the picture, what the children liked or disliked about the picture. If possible, they had to create their own story about the picture. 
Story books: Each caregiver received a story book, which they had to read to the children at bedtime and discuss the story with the children. Care was taken that the caregivers who were illiterate did not feel exposed. They received picture books and were asked to discuss the pictures with the children, and to let the children tell a story about the pictures. Otherwise other family members were asked to read the story to the children.

Magazines: Each caregiver received a few old magazines, which they had to use to read the children's sections to their children, or to cut out any pictures the children liked and stuck them in a book. They had to discuss the children's pictures with them. They were encouraged to make their own picture books with the children.

\section{A sense of belonging in the community}

All the caregivers were asked to identify one person in their immediate neighbourhood who could act as a substitute if the caregiver was unavailable. It had to be someone who could be trusted, with whom the children felt comfortable, and to whom they could turn in times of need. The caregivers had to ensure that they had a standing agreement with such a person that the children could go there whenever there was a need and the caregiver was unavailable. The children should be informed of this agreement and the name and contact details should be given to the social worker.

\section{Recording of activities}

The caregivers were asked to do as many as possible of the activities for the next two weeks. Every caregiver received a recording sheet. The facilitator ensured that everybody knew how to complete it. The caregivers who could not read had to ask someone else to help them with the recording. They were requested to record all the activities they performed with the children. A follow-up group meeting during which the results were discussed took place after two weeks.

\section{EVALUATION AND ADVANCED DEVELOPMENT}

After the contents of the proposed intervention has been determined, the fifth step of the design and develop model entails that an experimental design must be selected, and that data must be collected and analysed (De Vos \& Strydom, 2011:485). This was done by handing the following set of bibliotherapeutic techniques to social workers to test with children, as well as doing a training session with caregivers .

\section{Selecting an experimental design}

The purpose of this research project was to develop bibliotherapeutic techniques that would enhance a sense of belonging in children in fractured families from disadvantaged communities. The objectives were therefore to provide social workers with such techniques to use in their therapy with children, as well as information for a training session to raise the knowledge base and awareness of the caregivers regarding the children's need for belonging. The aspects that were evaluated were consequently whether the proposed techniques were comprehensive, feasible and user-friendly, as well as whether the training of the caregivers succeeded in raising their awareness and provided them with the information and means to complete activities with the children. 
The intention of this research project was not to measure the level of the sense of belonging in the children, but only to provide the means with which a sense of belonging could be enhanced. One of the aspects that was measured was the feasibility of the bibliotherapeutic techniques.

The proposed bibliotherapeutic techniques to be used by social workers in their therapy with children were evaluated by the social workers by means of evaluation forms. Eight social workers were asked to test and evaluate the techniques. These activities took place under field conditions, as the same people who were initially involved in the focus groups in phase two were asked to evaluate the intervention programme. The social workers worked in the community and were aware of the conditions and problems of the children and caregivers.

Another aspect that had to change was the caregivers' knowledge about a sense of belonging. In this case it is the knowledge level of the caregivers regarding a sense of belonging. Because the same caregivers who were involved in the focus groups were part of the experimental group of nine caregivers, the baseline of their knowledge level was already known. Their knowledge about this aspect was again tested after the intervention took place by means of the recording sheets and by interviewing the children who participated in the activities.

\section{Evaluation of the techniques for social workers}

The bibliotherapeutic techniques were given to eight social workers to test and evaluate. They had to comment on each activity and evaluate whether the instructions were clear, workable, had the desired outcome and whether they will use it in future. They had to complete an evaluation form, which was summarised by the researcher. Adaptations were made on the basis of their responses. Some of the social workers commented that they would like a short refresher course about a sense of belonging and the effects that a lack thereof has on a child. This opportunity can also be used to train the social workers in the presentation of the training of the caregivers.

\section{Evaluation of the training of caregivers}

In order to evaluate the effectiveness of the training of the caregivers, as well as the extent to which they completed the activities, focus group meetings were held with the children in their care, as well as with the caregivers. The following information was gained from the groups.

\section{Evaluation of the children's experiences of the implementation of the sense of belonging activities}

A focus group meeting comprising of the children in the care of the caregivers involved in the training session was held in order to determine how they experienced the activities. Their permission and that of their caregivers was obtained to record the group with a video camera. The group meeting was informal and started with a game to put the children at ease. They were then encouraged to talk about the activities their caregivers did with them during the previous two weeks. 
From their responses it was clear that all the caregivers were very conscientious in obeying all the instructions in implementing the activities. The children liked all the activities and their responses confirmed the finding in phase two that it is not really the activity itself that is important to the children, but the fact that their caregivers spent time with them. The children's favourite activities were those related to the emotions card, snakes and ladders, stories, books and magazines. The younger children enjoyed the nurturing activities, but the older ones scoffed at them.

While the discussion was taking place, the children could either colour in pictures, or make a collage of important aspects of their lives by using magazine pictures. Some children who chose to colour in nevertheless took some magazines and tried to hide them from the other children. They clearly loved to page through magazines, but because of their economic situation magazines are a luxury item which their caregivers could not afford. This led to the realisation that old magazines can be used with great success to create stories. Using magazine pictures would also be a solution to the problem relating to the fact that some of the caregivers cannot read. New and creative ways must be found to supply the caregivers with old magazines.

\section{Evaluation of the caregivers' experience with the utilising of the techniques}

The caregivers who were involved in the training session met after two weeks for an evaluation session. They were asked to complete activity sheets on all the activities they had done during the previous two weeks. During the meeting they were asked about their experiences when doing the activities, the children's reactions and the feasibility of the techniques. This session was also videotaped with their permission.

The overwhelming response of the caregivers was that they enjoyed doing the activities with the children, the children reacted very positively to the activities and that they created a closer relationship between them and the children. They mentioned a sideeffect that had not been foreseen, namely that the rest of the family voluntarily took part in the activities and that this led to positive bonding between all the family members.

From the caregivers' responses it appeared that implementing the emotion cards, snakes and ladders and physical nurturing were the favourite activities, and that they did them on a daily basis. It is possible that the novelty of these activities will wear off in time, but it is also evident that the caregivers are willing to try out new approaches and to cooperate, if they are provided with the necessary tools and understand why they have to do it.

A surprising fact was that most of the caregivers followed the suggestion to teach their children some of the old games that they played as children. They reported that they had great fun in doing so. This created a relaxed and accommodating atmosphere in the home, which brought them closer to the children. All the caregivers who did this reported that they enjoyed the games and it helped them to relax. All of those who could, did read the books to the children. One of the two illiterate people asked a family member to read the story to the children. The other person did not have the opportunity to ask someone to read the book, but she did spend some time with the children looking at the magazines. 
The caregivers were evaluated in an informal way to determine whether they understood the rationale behind the activities. From their responses it was clear that they understood at least the most important aspect, which is to create a sense of belonging in the children in their care. One caregiver commented that she could not believe that simple, everyday and easy activities could have such an effect on the emotions in the house, but after she experienced it, she wanted to continue with it. It was clear that their knowledge level regarding the importance of a sense of belonging and ways in which it can be achieved improved after the training and the completing of the activities.

The caregivers were motivated to continue with the activities. They seemed willing and eager to do them and expressed a need to meet on a regular basis to discuss the problems they have and to share possible solutions with each other. From this request the idea evolved that they want to pass on their children's clothes that are too small to the others. This excellent idea led to the further realisation that they could also trade and borrow books and other aids, such as play dough or puzzles. This will expand the limited poolof available books and educational toys. These suggestions are concrete ways in which the social capital in the community can be strengthened.

\section{REFINING THE BIBLIOTHERAPEUTIC TECHNIQUES}

The last step in phase five is to refine the intervention. According to De Vos and Strydom (2011:486), the necessary changes must be made in order to ensure that all errors are corrected. This involved attending to the techniques for social workers and the training for caregivers.

\section{Techniques for social workers}

With the exception of a few recommendations, the social workers felt that most of the techniques could be used in their original form. The whole set of activities was refined by suggesting that an arch-lever file must be used for each child. The social worker and child can decorate the file and write the child's name on the front, with the title "My Book of Belonging". All the documentary items relating to the activities must be kept in this file and the child can keep it after the therapy is completed. Other stories, notes or drawings can also be added. This will raise the child's self-awareness and enhance his or her sense of belonging.

\section{Training for caregivers}

The contents of the training programme for the caregivers remain unaltered and will be bound in a manual for the use of the social workers. Several suggestions were added after considering the comments of the children and caregivers.

- A follow-up session must take place after two weeks to evaluate the caregivers' experiences. This serves as added motivation for the caregivers to complete the activities.

- It is important that the caregivers who are involved in the training programme should keep in touch with each other. This serves as an additional motivation and strengthens the social capital in the community. 
404

- A group session once a term will serve as a further motivation to continue with the activities. It will also encourage and support the caregivers, who often feel overwhelmed with their situation.

- The social workers must build up a collection of books and magazines, which can be distributed among the caregivers. They can swap the books at group meetings. The caregivers do not have the means to purchase these items.

- The same can be done with educational toys. Board games seem to be a favourite among the children and families, and different games can be rotated between the families.

\section{RECOMMENDATIONS AND LIMITATIONS}

From the responses of the social workers, it seemed that they have a need for a refresher course on a sense of belonging and to train the caregivers in engaging with the children in order to enhance a sense of belonging. The content of the course should include the following:

- The importance of a sense of belonging;

- The challenges experienced by caregivers from fractured families in disadvantaged communities;

- The concept of social capital and how to utilise it with regards to enhancing a sense of belonging;

- Bibliotherapy and bibliotherapeutic techniques;

- The contents and implementation of the bibliotherapeutic techniques;

- The contents and training of the caregivers in enhancing the children in their care's sense of belonging.

As each child's situation is different, the social workers must use their own discretion as to which of the bibliotherapeutic activities to use at a certain time. With the exception of utilising the emotions card and the snakes and ladders game, only one activity should be done per session.

Regarding the training of the caregivers, their disadvantaged circumstances should always be kept in mind and nothing should be taken for granted. It should, for example, not be taken for granted that everybody can read and write, or that every household has magazines or books. Everything that the caregivers would need to do the activities with their children must be provided, as they do not have the means to buy items such as crayons and colouring books.

Follow-up sessions for the caregivers are vital to the success of the intervention. They serve several purposes, such as to keep them motivated to continue with the activities, and they provide support and relief from their situation as well as serving as a source of social capital.

The suggestion from the caregivers to meet at regular intervals and to exchange clothes, toys and games is something that is worth exploring. 
Several limitations were experienced. The fact that some of the caregivers are illiterate is a serious limitation in proposing bibliotherapeutic techniques. It was therefore necessary to be creative in order to provide other means by which stories can be shared, such as picture books and magazines.

The poverty and lack of resources in the community were another limitation. The caregivers and children do not have access to libraries and books. Even a relatively cheap game like snakes and ladders is a novelty that was thoroughly enjoyed by the whole family. This places an extra burden on the social workers in the sense that such games must be provided.

Some of the caregivers are old and sickly, and have difficulty in getting to the venue for meetings. Transport has to be provided for them.

\section{CONCLUSION}

The needs of the children in fractured families from disadvantaged communities regarding a sense of belonging, their social workers as well as the caregivers' requirements to provide for this need of the children were taken into account when the intervention was developed. It transpired that the children did not always experience a sense of belonging with their caregivers, and that the caregivers were unaware of this need. The intervention consequently focused on two aspects, namely to provide bibliotherapeutic techniques for the social workers to facilitate the development of a sense of belonging in the children, and to provide a training manual for the caregivers in order to raise their awareness about the children's need for a sense of belonging, and to teach them activities to enhance the children's sense of belonging.

The researcher developed bibliotherapeutic techniques for the use of the social workers, as well as a training session for the caregivers. After they were tested and evaluated by the social workers and caregivers, the necessary refinement was done in order to make them more effective. They are now ready for the sixth phase of the intervention model, i.e. their dissemination.

\section{REFERENCES}

AFRICAN CHARTER ON THE RIGHTS AND WELFARE OF THE CHILD. 1990. Article 12. [Online] Available: www.unhcr.org.refworld/docid/3ae6b38c.html [Accessed: 30/07/2012].

ALDERFER, C.P. 1989. Theories reflecting my personal experience and life development. The Journal of Applied Behavioural Science, 25(4):351-365.

BARBER, P. 2006. Becoming a practitioner researcher. a Gestalt approach to holistic inquiry. London: Middlesex University Press.

BARKER, B.L. 2003. The social work dictionary $\left(5^{\text {th }}\right.$ ed). Washington, DC: NASW Press. 
406

BECK, M. \& MALLEY, J. 2003. A pedagogy of belonging. The International Child and Youth Care Network, 50:(March). [Online] Available: http://cyc-net.org/cyconline. [Accessed: 18/02/2010].

BERLIN, L.J. 2005. Interventions to enhance early attachments: the state of the field today. In: BERLIN, L.J., ZIV, Y., AMAYA-JACKSON, L. \& GREENBERG, M.T. (eds). Enhancing early attachments: theory, research, intervention and policy. New York, NY: Guilford, 3-33.

BOOTH, P.B. \& JERNBERG, A.M. 2010. Theraplay: helping parents and children build better relationships through attachment-based play ( $3^{\text {rd }}$ ed). San Francisco, CA: Jossey-Bass.

BOWLBY, J. 1982. Attachment and loss, Vol. 1. New York, NY: Basic Books.

BRENDTRO, L.K., BROKENLEG, M. \& VAN BOCKERN, S. 2002. Reclaiming youth at risk. Our hope for the future (rev ed). Indianapolis, In: National Educational Service.

BURNS, G.W. 2005. 101 Healing stories for kids and teens. Using metaphors in therapy. Hoboken, N.J: John Wiley.

COSTELLO, P.J.M. 2000. Thinking skills and early childhood education. London: David Fulton.

DE VOS, A.S. \& STRYDOM, H. 2011. Intervention research. In: DE VOS, A.S., STRYDOM, H., FOUCHé, C.B. \& DELPORT, C.S.L. Research at grass roots for the social sciences and human service professions $\left(4^{\text {th }} \mathrm{ed}\right)$. Pretoria: Van Schaik Publishers, 473-490.

DING, S. \& LITTLETON, K. 2005. Children's personal and social development. Oxford: Blackwell.

ELLIOT, D.S., MENARD, S., RANKIN, B., ELLIOT, A., WILSON, W.J. \& HUIZINGA, D. 2006. Good kids from bad neighbourhoods. New York, NY: Cambridge University Press.

ERIKSON, E. 1969. Childhood and society. New York, NY: W.W. Norton.

FITZGERALD, J.A. 2007. Bibliotherapy. Encyclopedia of mental disorders. [Online] Available: http://www.minddisorders.com [Accessed: 28/12/2008].

FRASER-MACKENZIE, S. 2011. The African collection. Nine stories about physical and learning difficulties to promote acceptance and empower all children and caregivers. Knysna: Knysna Press.

GIRLS AND BOYS TOWN. 2011. Bookmark: six things a child needs to hear. [Online] Available: www.girlsandboystown.org.za [Accessed: 30/06/2012].

HAMILTON, A. 2005. The circle of courage. [Online] Available: http://www. parenting.org.za [Accessed: 23/06/ 2009]. 
HENDRICKS, C.G. \& HENDRICKS, J.E. 1998. When children are victims: making the case for bibliotherapy. American Reading Forum Yearbook Online. [Online] Available: http://americanreadingforum.org/yearbook/yearbooks/98 [Accessed: 27/05/2012].

HEPWORTH, D.H. \& LARSEN, J. 1993. Direct social work practice. Theory and skills $\left(4^{\text {th }}\right.$ ed $)$. Belmont, CA: Wadsworth.

HOLBORN, L. \& EDDY, G. 2011. First steps to healing the South African family. Johannesburg: South African Institute of Race Relations.

JOYCE, P. \& SILLS, C. 2010. Skills in Gestalt counselling and psychotherapy. London: Sage Publications.

KAREN, R. 1998. Becoming attached: first relationships and how they shape our capacity to love. Oxford: Oxford University Press.

KIRCHNER, M. 2004. Gestalt therapy theory: an overview. Gestalt! (4(3). Gestalt Global Corporation..

KRIEL, E., RADEMEYER, M. \& RÖHRS, E. 2010. Voices of hope. Healing stories for Africa's children. Cape Town: Jelly Beanz.

LUCAS, J.R. 2000. 1001 Ways to connect with your kids. Carol Stream, IL: Tyndale House.

MALCHIODI, C.A. \& GINNS-GRUENBERG, D. 2008. Trauma, loss and bibliotherapy. The healing power of stories. In: MALCHIODI, C.A. (ed). Creative interventions with traumatized children. New York, NY: Guilford, 167-185.

MASLOW, A.H. 1970. Motivation and personality. New York, NY: Harper and Row.

MAX-NEEF, M.A. 1991. Human scale development. Conception, application and further reflections. New York, NY: Apex.

McWHIRTEN, J.J. 2007. At risk youth. Victoria: Thomson Australia.

MEYER, W.F., MOORE, C. \& VILJOEN, H.G. 2008. Personology: from individual to ecosystem $\left(4^{\text {th }}\right.$ ed $)$. Johannesburg: Heinemann.

MILLER, J.M., LENDER, D., RUBIN, P.B. \& LINDAMAN, S. 2010. Theraplay for children who are adopted or in foster care. In: BOOTH, P.B. \& JERNBER, A.M. Theraplay: helping parents and children build better relationships through attachment-based play. San Francisco, CA: Jossey-Bass.

MINUCHIN, P., COLAPINTO, J. \& MINUCHIN, S. 2007. Working with families of the poor $\left(2^{\text {nd }}\right.$ ed). New York, NY: Guilford.

MORIN, V.K. 1999. Fun to grow on: engaging play activities for kids with teachers, parents and grandparents. Chicago, IL: Magnolia Street Publishers.

OAKLANDER, V. 2003. Gestalt Play Therapy. In: SCHAEFER, C.E. (ed) Foundations of play therapy. Hoboken, NJ: John Wiley, 143-155. 
408

OELOFSEN, I. 2012. Facilitating sense of belonging of children in fractured families from disadvantaged communities, utilising bibliotherapeutic techniques. Potchefstroom: North-West University. (PhD thesis)

PARDECK, J.T. 1998. Using books in clinical social work practice. A guide to bibliotherapy. New York: Haworth.

PARDECK, J.T. 2005. Using bibliotherapy in family health social work practice with children of divorce. In: YUEN, F.K.O. Social work practice with children and families: a family health approach. New York, NY: Haworth, 45-53.

PERLS, F. 1973. Gestalt approach and eye witness to therapy. Los Altos, CA: Science and Behavior Books.

RECOB, A. 2008. Bibliotherapy: when children need books. Bloomington, IN: iUniverse.

ROTHMAN, J. \& THOMAS, E.J. 1994. Intervention research. Design and development for human service. New York, NY: Haworth.

RUBIN, R.J. 1978. Bibliotherapy: a guide to theory and practice. London: Oryx .

SANTROCK, J.W. 2006. Life-span development $\left(10^{\text {th }}\right.$ ed). New York, NY: McGrawHill.

SHARF, R.S. 2004. Theories of psychotherapy and counseling. Belmont, CA: Thomson.

SMITH, M.K., COWIE, H. \& BLADES, M. 2003. Understanding children's development $\left(4^{\text {th }}\right.$ ed $)$. Oxford: Blackwell.

SORENSEN, J. 2008. Overcoming loss: activities and stories to help transform children's grief and loss. London: Jessica Kingsley.

SUNDERLAND, M. 2000. Using story telling as a therapeutic tool with children. Milton Keynes, UK: Speechmark.

TALBOT, J.P. \& THORNTON, L. 2009. A chance to play: a manual promoting play for children in South Africa. Braamfontein: Fishwicks.

TOERIEN, M. 2001. Die benutting van Gestaltspelterapie op die aanpassing van die middelkinderjare-kind in ' $\mathbf{n}$ kinderhuis. Pretoria: Universiteit van Pretoria. (MA verhandeling).

UNITED NATIONS. 1989. Conventions on the right of the child. Children's right to play, recreation, leisure, art and cultural activities. Article 31. [Online] Available: http://www.unicef.org/crc [Accessed: 07/07/2007]. 
YONTEF, G.M. 2000. Why relational Gestalt therapy? Gestaltpsychotherapy Column \& Forum. [Online] Available: http://www.gestaltpsychotherapie. de/column_01.01.htm [Accessed: 03/01/2007].

YUEN, F.K.O. 2005. Social work practice with children and families. A family health approach. New York, NY: Haworth Press.

Dr Iralda Oelofsen (Postgraduate student), Dr Herman Grobler, Centre for Child, Youth and Family Studies, Faculty of Health Sciences, North-West University, Potchefstroom, South Africa. 